\title{
Regulation of Astrocyte Functions in Multiple Sclerosis
}

\author{
Michael A. Wheeler ${ }^{1}$ and Francisco J. Quintana ${ }^{1,2}$ \\ ${ }^{1}$ Ann Romney Center for Neurologic Diseases, Brigham and Women's Hospital, Harvard Medical School, \\ Boston, Massachusetts 02115 \\ ${ }^{2}$ The Broad Institute of MIT and Harvard, Cambridge, Massachusetts 02142 \\ Correspondence: fquintana@rics.bwh.harvard.edu
}

\begin{abstract}
Astrocytes play complex roles in health and disease. Here, we review recent findings on molecular pathways that control astrocyte function in multiple sclerosis (MS) as well as new tools for their investigation. In particular, we describe positive and negative regulators of astrocyte-mediated pathogenesis in MS, such as sphingolipid metabolism and aryl hydrocarbon receptor signaling, respectively. In addition, we also discuss the issue of astrocyte heterogeneity and its relevance for the contribution of astrocytes to MS pathogenesis. Finally, we discuss how new genomic tools could transform the study of astrocyte biology in MS.
\end{abstract}

G lial cells play diverse roles in the central nervous system (CNS) in health and disease. Astrocytes are the predominant glial cell in the CNS (Allen and Barres 2009; Sofroniew and Vinters 2010; Khakh and Sofroniew 2015), with important roles in the pathogenesis of neurologic diseases such as multiple sclerosis (MS). Although the prevailing view of astroglial cells has been that they are homogeneous, multiple astrocyte subpopulations have been shown to play important roles in synapse refinement (Stevens et al. 2007; Chung et al. 2013), cellular communication via $\mathrm{Ca}^{2+}$ waves (Srinivasan et al. 2015; Ma et al. 2016), and neurodegenerative disease (Mayo et al. 2014; Rothhammer et al. 2016, 2017a, 2017b; Liddelow et al. 2017). In recent years, renewed interest has mounted on the study of astrocyte populations (Christopherson et al. 2005; Allen et al. 2012; Zamanian et al.
2012; Bayraktar et al. 2014; Mayo et al. 2014; Khakh and Sofroniew 2015; Rothhammer et al. 2016; Zhang et al. 2016; Ben Haim and Rowitch 2017), fueled by the development of new technologies for genomic and single-cell analysis (Metzker 2010; Macosko et al. 2015). This review discusses the role of astrocytes in CNS inflammation, the pathways that regulate them, their heterogeneity, and emerging technologies to study astrocyte diversity.

\section{ASTROCYTES IN THE CONTEXT OF DISEASE}

Astrocytes participate in critical aspects of CNS development and homeostasis such as synapse maintenance and refinement, neurotransmission, phagocytosis, and blood-brain barrier (BBB) formation. Consequently, astrocyte perturbations in disease are likely to have deleteri-

Editors: Howard L. Weiner and Vijay K. Kuchroo

Additional Perspectives on Multiple Sclerosis available at www.perspectivesinmedicine.org

Copyright (C) 2019 Cold Spring Harbor Laboratory Press; all rights reserved; doi: 10.1101/cshperspect.a029009

Cite this article as Cold Spring Harb Perspect Med 2019;9:a029009 
M.A. Wheeler and F.J. Quintana

ous effects on neural function. Indeed, whereas important data are emerging with regard to the role of astrocytes in neuropsychiatric disorders (Dallerac and Rouach 2016; Blanco-Suarez et al. 2017), animal models of neurodegenerative disease provide useful experimental systems to study general principles related to the pathogenic role and regulation of astrocytes. A landmark study by Barres and coworkers recently identified molecular mechanisms that promote the development of a neurotoxic subpopulation of astrocytes (named A1 astrocytes) (Liddelow et al. 2017). The investigators found that interleukin (IL)- $1 \alpha$, in combination with tumor necrosis factor $\alpha$ (TNF- $\alpha)$, and complement component 1 subcomponent $\mathrm{q}(\mathrm{C} 1 \mathrm{q})$, induces a transcriptional program that induces a neurotoxic phenotype in astrocytes that they termed A1 astrocytes.
A1 astrocytes are strong drivers of synapse elimination and neuronal cell death. Liddelow et al. identified microglia as the main cellular driver for the induction of neurotoxic A1 astrocytes, which they detected in MS and other neurodegenerative diseases such as Alzheimer's disease, Parkinson's disease, and amyotrophic lateral sclerosis. The investigators also identified a second subpopulation of astrocytes (A2 astrocytes) that is potentially neurotrophic (Zamanian et al. 2012; Liddelow et al. 2017). These findings highlight the profound effects of glial cells on neural integrity (Fig. 1). These findings also raise the question of whether other myeloid cells, such as inflammatory monocytes recruited to the CNS in inflammatory diseases such as MS, can also promote astrocyte differentiation to the neurotoxic A1 phenotype through these and additional pathways.

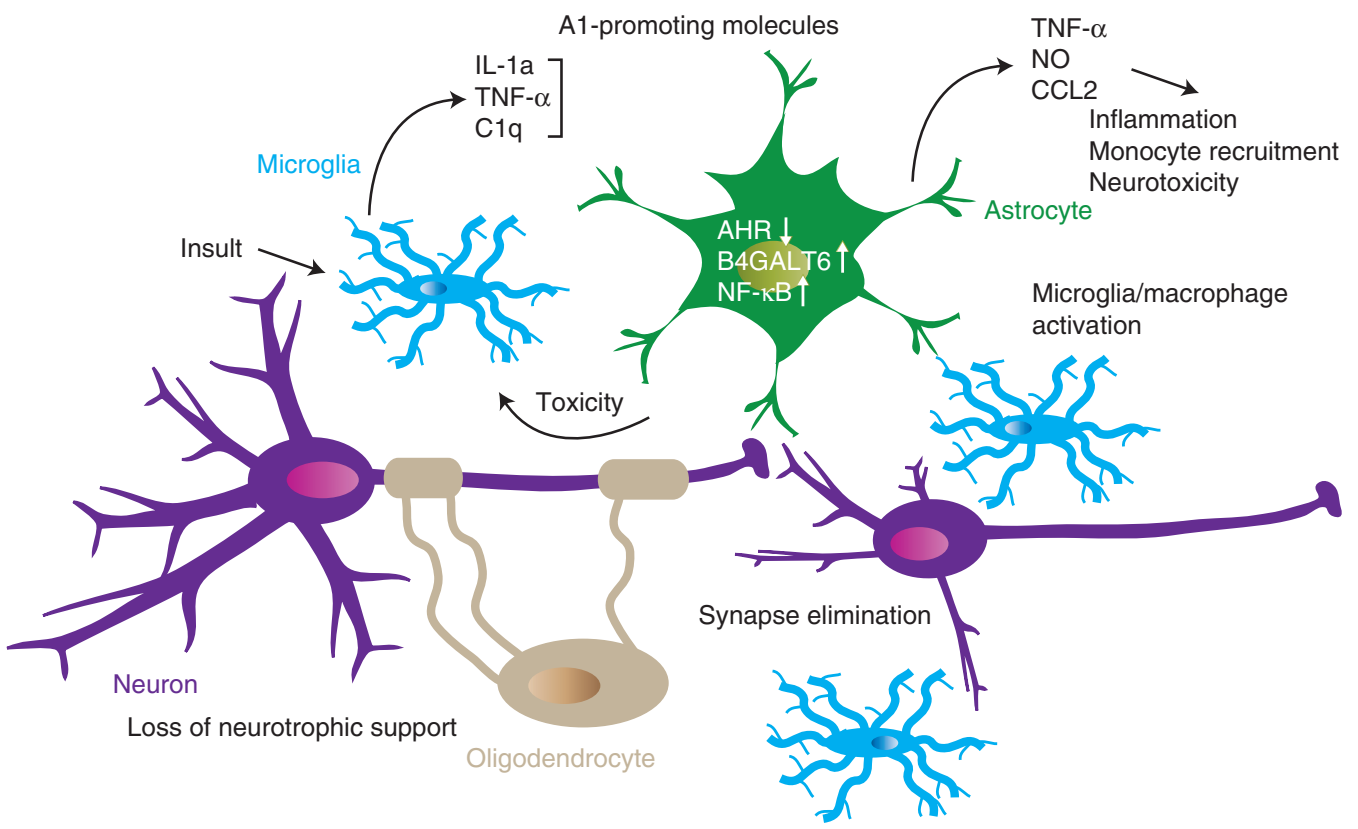

Figure 1. Cellular cross talk in the central nervous system (CNS). Microglia activated by infection, neurodegeneration, or other triggers produce molecules that induce a proinflammatory (A1) phenotype in astrocytes. A1 astrocytes prevent synapse formation and decrease neurotrophic support, also impairing oligodendrocyte function. Proinflammatory molecules act on astrocytes to boost sphingolipid metabolism, nuclear factor (NF)- $\kappa \mathrm{B}$ transcriptional activity, and cytokine production while down-regulating anti-inflammatory aryl hydrocarbon receptor (AHR) transcriptional activity. As a result, astrocytes secrete neurotoxic molecules such as tumor necrosis factor $\alpha$ (TNF)- $\alpha$ and nitric oxide (NO), which amplify this neurotoxic state, and also CCL2, which recruits proinflammatory immune cells. IL, Interleukin. 
Astrocytes also play an active role in neuronal repair. In response to acute injury, astrocytes form a glial scar, which has been classically viewed as an inhibitory barrier to axonal regrowth in the mature CNS (Silver and Miller 2004; Anderson et al. 2014). However, it was recently shown by Sofroniew and coworkers that astrocytic glial scars also produce factors that enhance neuronal regeneration (Anderson et al. 2016). In these studies, the investigators profiled ribosomal messenger RNA (mRNA) using the RiboTag approach, which enables cell-specific expression of hemagglutinin (HA)tagged mRNA-translating ribosomes that can be immunoprecipitated to sequence the bound mRNA (Sanz et al. 2009). Using this approach to analyze astrocytes in a model of spinal cord injury, the investigators detected the mixed expression of axonal growth-permissive molecules (e.g., the extracellular matrix protein laminin), as well as molecules that suppress axonal growth such as lectican family members (Anderson et al. 2016). Strikingly, the investigators observed the virtual absence of the neurotrophic factors neurotrophin-3 (NT-3), brain-derived neurotrophic factor (BDNF) and glial-derived neurotrophic factor (GDNF). Administration of NT-3/BDNF to the injured spinal cord stimulated axonal regrowth but only in the presence of the glial scar. Thus, these findings suggest that reactive astrocytes are essential for neuronal repair either by providing an axonal scaffold for neurons and/or via the production and amplification of neurotrophic signals. Taken together, these findings highlight the heterogeneity of astrocytic responses and the importance of identifying the molecular mechanisms that control these responses for their therapeutic manipulation.

\section{ASTROCYTES IN MULTIPLE SCLEROSIS}

MS is an autoimmune demyelinating disease of the CNS in which the adaptive immune system wages an attack against the myelin that insulates axons (Rothhammer and Quintana 2015, 2016). The majority of patients presents a relapsing remitting (RRMS) clinical course at diagnosis in which the appearance of disability is intermittent, followed by complete or partial recovery.
Over time, however, MS can develop a secondary progressive (SPMS) clinical course characterized by the progressive and irreversible accumulation of neurologic disability (Stys et al. 2012).

The importance of astrocytes in MS has been recognized for almost two centuries. In the 1800s, Jean-Marie Charcot identified astrocytes as critical components of MS lesions in the CNS of patients (Charcot 1868). New genomic techniques now allow the characterization of the pathways that control astrocyte dysfunction in MS, while also identifying specific transcriptional programs associated with distinct astrocyte subpopulations.

Several molecules linked to MS can control astrocyte activity, including a variety of cytokines and chemokines (Rothhammer and Quintana 2015), metabolites such as ATP (Takenaka et al. 2016), and lipids generated during apoptosis (Husemann et al. 2002), among others (Fig. 2). These signaling pathways converge on common downstream transcriptional programs that activate proinflammatory molecules such as the activator protein 1 transcriptional complex, nuclear factor $\kappa$-light-chain-enhancer of activated $B$ cells $(\mathrm{NF}-\kappa \mathrm{B})$, and signal transducers and activators of transcription proteins (STATs) (De Keyser et al. 2010). The activation of these pathways contributes to the pathology of MS and other neurologic diseases through astrocyte intrinsic and extrinsic mechanisms.

In addition to the effects of CNS-resident cells, the breakdown of the BBB that characterizes RRMS (Sofroniew 2015) leads to CNS infiltration by $\mathrm{T}$ cells and inflammatory monocytes, increasing local levels of proinflammatory cytokines such as the A1 astrocyte-inducing combination of C1q, IL-1, and TNF- $\alpha$ (Goverman 2009; Steinman 2009, 2014). BBB breakdown is less prominent during SPMS, in which neurodegeneration is thought to be driven by a chronic innate immune response involving CNS-resident cells (Rothhammer and Quintana $2015,2016)$. Indeed, it should be noted that IL-1 and TNF- $\alpha$ are also secreted by astrocytes themselves and might function in an autocrine or paracrine manner to amplify and/or stabilize the neurotoxic A1 phenotype (Farez et al. 2009; 
M.A. Wheeler and F.J. Quintana

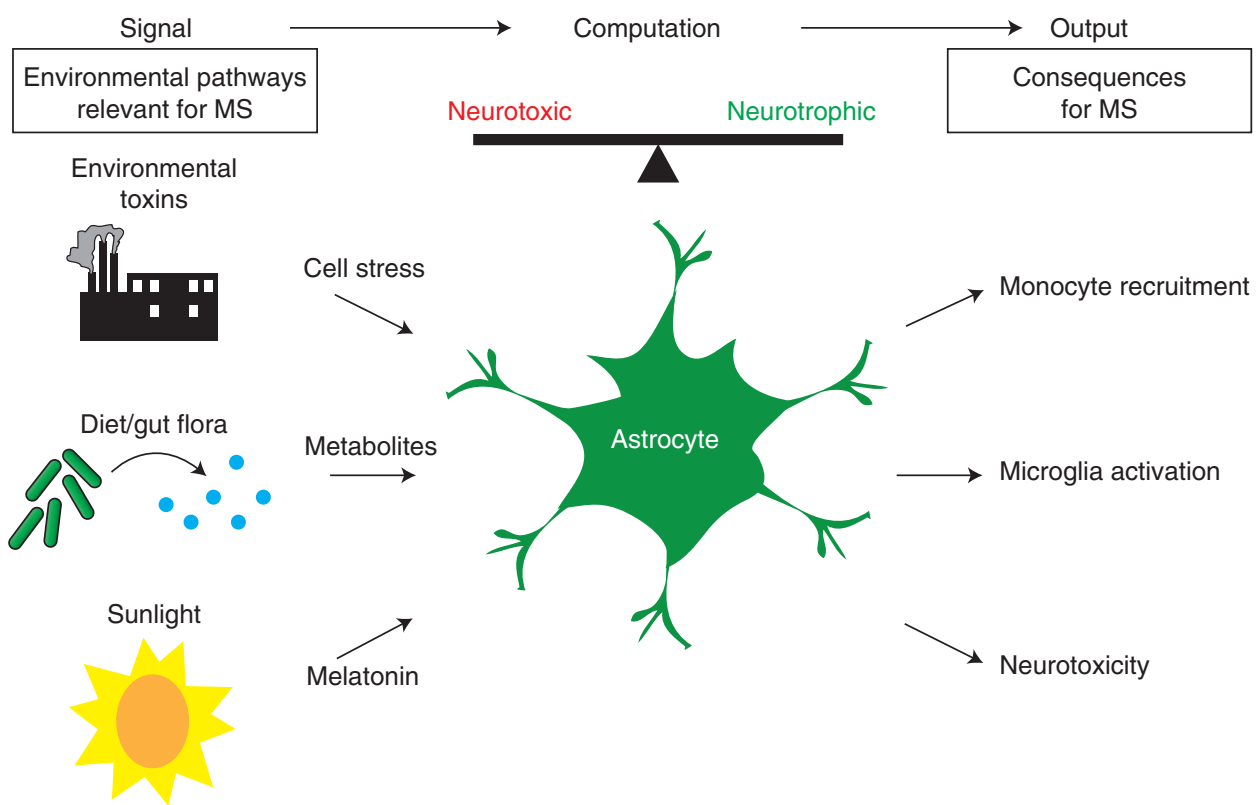

Figure 2. Astrocyte function in multiple sclerosis (MS). Environmental factors described to affect MS onset and progression, such as environmental toxins, the diet, metabolites generated by the commensal flora, and sunlight, may act on astrocytes to modulate MS-relevant pathogenic functions.

Mayo et al. 2014; Rothhammer et al. 2016, 2017b).

As discussed above, astrocytes participate in virtually every important aspect of neural circuit assembly and maintenance, consistent with emerging evidence that they play pivotal roles in neurologic diseases such as MS (Seifert et al. 2006; Basso et al. 2008; Nair et al. 2008; Lassmann 2014; Mayo et al. 2014; Xie and Yang 2015; Ludwin et al. 2016; Rothhammer et al. 2016, 2017b; Liddelow et al. 2017). Therefore, the identification of astrocyte-intrinsic pathways that control CNS inflammation, modulate neuronal health, and maintain $\mathrm{BBB}$ integrity may guide new therapeutic approaches, particularly for the progressive phase of MS for which existing drugs offer limited benefit.

\section{ARYL HYDROCARBON RECEPTOR (AHR) SIGNALING, A NEGATIVE REGULATOR OF ASTROCYTE-DRIVEN CNS PATHOLOGY}

Several molecular pathways have recently been linked to neurotoxic and neurotrophic astrocyte populations relevant to MS. In particular, it is useful to identify astrocyte-intrinsic signaling pathways that boost or limit CNS inflammation and neurodegeneration, as these are potential targets for therapeutic intervention.

We recently described a new role for the AHR in controlling astrocyte-driven pathology in MS (Quintana 2013a,b; Rothhammer et al. 2016). AHR is a ligand-activated transcription factor in which activity is regulated by a broad range of molecules provided by the environment, the diet, the commensal microbiota, and the metabolism (Quintana 2013a; Quintana and Sherr 2013). On ligand binding, AHR translocates to the nucleus to regulate the expression of diverse target genes involved in multiple biologic activities, including detoxification such as Cyp1a1 (Chang and Puga 1998), or inflammatory genes involved in the immune response such as NF- $\kappa \mathrm{B}$ (Rothhammer et al. 2016; Yeste et al. 2016), among others. Thus, AHR plays an important role in the control of specific transcriptional programs by environmental factors during autoimmune inflammatory diseases. 
Our studies on the transcriptional program of astrocytes during the course of experimental autoimmune encephalomyelitis (EAE), the mouse model of MS, detected a transcriptional response suggestive of type I interferon (IFN-I) signaling in astrocytes (Rothhammer et al. 2016). Interestingly, IFN-I-induced AHR expression in astrocytes, triggering an AHRdependent anti-inflammatory response. The specific deletion of AHR in astrocytes led to worsened EAE and failure to recover. At the molecular level, AHR deletion resulted in exacerbated NF- $\kappa \mathrm{B}$ activation and increased expression of proinflammatory genes linked to the recruitment of inflammatory cells to the CNS, the activation of myeloid cells, and direct astrocytedriven neurotoxicity.

AHR activity is regulated by a broad collection of small molecules, some of which are produced in the metabolization of dietary tryptophan by gut commensal bacteria (Quintana and Sherr 2013; Stockinger et al. 2014). We found that AHR agonists provided by the diet and the gut flora cross the BBB to activate astrocyte-dependent anti-inflammatory responses that limit CNS inflammation during EAE (Rothhammer et al. 2016). Collectively, these findings identify a gut-brain axis by which small molecules provided by the gut flora reach the CNS to control astrocyte function and limit inflammation and neurodegeneration. This axis is likely to be relevant to multiple neurologic diseases.

In addition, it should be noted that different ligands are thought to induce ligand-specific conformational changes in AHR that direct its recruitment to different target genomic regions (Matikainen et al. 2001; Quintana and Sherr 2013; Quintana 2014). Thus, it is tempting to speculate that different AHR ligands may induce divergent transcriptional responses in astrocytes. Hence, environmental AHR ligands other than those provided by the gut flora, for example those provided by pollutants, may have different effects on CNS inflammation and neurodegeneration.

While analyzing patient samples, we detected decreased AHR activation in MS lesions as compared with controls, concomitant with lower levels of AHR agonists in serum. The origin of this decrease in circulating AHR agonists is currently unknown, although several mechanisms can potentially contribute to this observation. AHR agonists such as kynurenine are produced during inflammation (Platten et al. 2005; Bessede et al. 2014). Thus, it is possible that in the context of chronic inflammation the production of these endogenous AHR agonists is decreased, limiting the beneficial effects of AHR-driven anti-inflammatory mechanisms (Quintana 2013a,b; Quintana and Sherr 2013; Mayo et al. 2014; Rothhammer et al. 2017a). In addition, alterations in the gut flora have been recently identified in MS (Jangi et al. 2016). Thus, it is possible that deficits in AHR agonists reflect alterations in the gut flora of MS patients, as it has been recently described in inflammatory bowel disease (Lamas et al. 2016).

These findings also have implications for the treatment of MS and, potentially, other neurologic diseases. Therapeutic interventions aimed at boosting the production of physiologic AHR agonists, such as diet modification or probiotic supplementation may provide new therapeutic avenues for MS. In addition, BBB-permeable synthetic AHR agonists may provide a therapeutic tool to suppress pathogenic activities in astrocytes. Indeed, laquinimod, a drug being developed to treat MS (Palma and Pagola 2012; Bruck and Vollmer 2013; Luhder et al. 2017) has been recently reported to be a potent AHR agonist. Laquinimod crosses the BBB and ameliorates EAE (and potentially MS) in an AHR-dependent manner (Varrin-Doyer et al. 2014; Kaye et al. 2016). In a phase III clinical trial, laquinimod reduced brain atrophy in MS, a process thought to reflect neurodegeneration driven at least partially by astrocytes (Vollmer et al. 2014).

Finally, in the context of astrocyte heterogeneity, it is plausible that AHR up-regulation identifies a subpopulation of astrocytes with anti-inflammatory and neurotrophic activity. It would be interesting to see how this population of $\mathrm{AHR}^{+}$astrocytes is regulated by the gut-brain axis in different stages of MS and in other neurologic diseases affected by the microbiome (Hsiao et al. 2013; Buffington et al. 2016; Gacias et al. 2016). 
M.A. Wheeler and F.J. Quintana

\section{SPHINGOLIPID METABOLISM, A POSITIVE REGULATOR OF ASTROCYTE-DRIVEN CNS PATHOLOGY}

Our functional and transcriptional analyses of astrocytes in a chronic EAE model using nonobese diabetic mice (NOD-EAE) identified additional pathways involved in astrocyte regulation. It is important to note that NOD-EAE resembles several aspects of SPMS, including the progressive and irreversible accumulation of neurologic symptoms over time following an initial relapsing remitting phase. The depletion of reactive astrocytes during the relapsing remitting phase of NOD-EAE led to a significant worsening of the disease (Mayo et al. 2014) as reported in acute EAE models (Voskuhl et al. 2009; Toft-Hansen et al. 2011), reflecting the increased recruitment of peripheral leukocytes into the inflamed CNS. Conversely, reactive astrocyte depletion during the chronic phase of the disease led to a significant recovery from disease (Mayo et al. 2014), suggesting a significant role for astrocytes in driving disease progression in NOD-EAE. We analyzed the transcriptional profiles of astrocytes isolated during the acute and chronic/progressive phases of NOD-EAE to identify transcriptional programs associated with different functional roles of astrocytes in CNS inflammation. In astrocytes isolated during the chronic/progressive phase, we detected a significant up-regulation in the expression of the gene B4galt6, which codes for an enzyme that catalyzes the synthesis of lactosylceramide (LacCer) from the precursor molecule glucosylceramide (Chatterjee and Alsaeedi 2012). Indeed, EAE was worsened by LacCer administration. Conversely, pharmacological inhibition or astrocyte-specific knockdown of B4galt6 ameliorated disease. A role for B4GALT6 in driving CNS inflammation is also supported by our studies of MS samples, in which we detected increased B4GALT6 expression in astrocytes localized in MS lesions (Mayo et al. 2014). In MS samples, B4GALT6 expression colocalized with the expression of the chemokine CCL2 and the inflammation-linked enzyme inducible nitric oxide synthase (iNOS), suggesting that these markers identify an astro- cyte subpopulation that contributes to disease pathogenesis in MS and, possibly, other neurologic diseases.

\section{REGULATION OF ASTROCYTE FUNCTION BY ENVIRONMENTAL SIGNALS}

The findings discussed above raise questions regarding the regulation of astrocyte function during acute or chronic CNS inflammation and, consequently, during the different phases of MS. In the context of acute inflammation, astrocytes can limit immunopathogenesis in the CNS (Mayo et al. 2014; Rothhammer et al. 2016, 2017b). However, during chronic inflammation, astrocytes may contribute to disease pathogenesis and neurotoxicity. Obviously, these apparently opposing behaviors of astrocytes may reflect changes in the relative contribution to disease pathogenesis of different astrocyte populations and/or the activation of different genomic programs in the same astrocyte population.

It is likely that multiple factors modulate astrocyte function in disease. Indeed, our recent findings on the effects of microbial metabolites in the regulation of astrocyte function during MS identify a new role for environmental factors in the modulation of CNS inflammation and neurodegeneration through the regulation of astrocyte activity. Indeed, MS onset and progression are known to be influenced by multiple environmental factors, including sunlight and the diet (Farez et al. 2015a,b, 2016; Rothhammer and Quintana 2016; Rothhammer et al. 2016). For example, we recently reported that seasonal changes in night length modulate CNS inflammation through a mechanism mediated by melatonin. Melatonin acts directly on $\mathrm{T}$ cells to suppress the differentiation of proinflammatory IL-17-secreting $\mathrm{T}$ helper (Th) 17 cells (Farez et al. 2015b). Conversely, melatonin boosts the differentiation of type 1 regulatory $\mathrm{T}(\mathrm{Tr} 1)$ cells (Farez et al. 2015b), a population of Th cells with anti-inflammatory effects mediated by IL-10 and CD39 (Mimran et al. 2004; Apetoh et al. 2010; Gandhi et al. 2010; Wu et al. 2011; Mascanfroni et al. 2015; Takenaka et al. 2016; 
Regulation of Astrocyte Functions in MS

Gabriely et al. 2017). IL-10 produced by $\operatorname{Tr} 1$ cells suppresses disease-promoting activities in astrocytes (Mayo et al. 2016). Thus, Tr1 cells induced by melatonin, AHR agonists, or other environmental factors may suppress diseasepromoting transcriptional programs in astrocytes during MS.

Interestingly, it was recently reported that astrocytes are intrinsic components of the circadian clock in the suprachiasmatic nucleus (SCN) (Brancaccio et al. 2017). Whereas SCN neurons fire in daylight, astrocytes are more active at night (Brancaccio et al. 2017), suggesting that the effects of sunlight exposure in MS may also involve altered activation of astrocytes with neurotrophic or neurotoxic activity. An outstanding question, therefore, is the identification of molecular pathways that control neurotoxic and neuroprotective astrocyte populations to develop new therapeutic approaches for neurologic disease.

\section{NEW TOOLS FOR ASSESSING THE ASTROCYTIC CONTRIBUTION TO MS}

The development of new tools for genomic analysis has expanded our ability to identify and understand molecular pathways that contribute to the pathogenesis of multiple diseases (Fig. 3) (Shendure and Ji 2008; Metzker 2010). For instance, next-generation sequencing (NGS) enables the detection of genomic information at high throughput, yielding gigabases of sequencing data per single run. New methods have emerged to combine the high-throughput analysis of chromatin (Meyer and Liu 2014) and RNA expression (Byron et al. 2016). These methods show both advantages and disadvantages. For instance, chromatin immunoprecipitation followed by sequencing (ChIP-seq) enables directed isolation of a chromatin modification or transcription factor through antibody-mediated pull-down (Barski et al. 2007; Johnson et al.

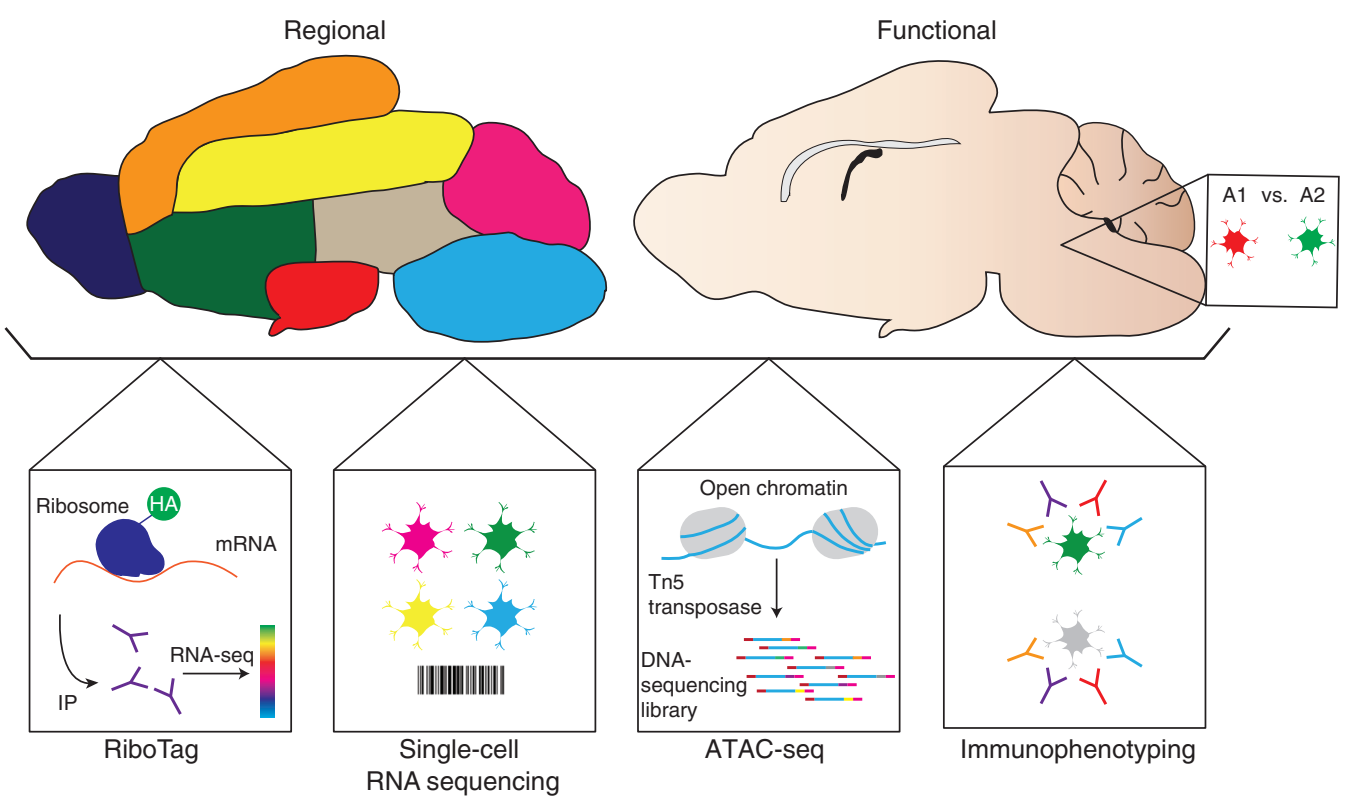

Figure 3. Tools to study astrocytes in multiple sclerosis (MS). Tools available to study astrocyte heterogeneity (regional vs. functional). The RiboTag approach allows the analysis of messenger RNA (mRNA) expression using genetically defined samples. Single-cell RNA sequencing provides a method to identify new cell populations based on their unique transcriptional profiles. Assay for transposable accessible chromatin (ATAC)-seq enables the analysis of open chromatin through the addition of sequencing adaptors into accessible genomic regions. Immunophenotyping enables the analysis of astrocyte populations defined on the basis of surface molecule expression detectable by flow cytometry. HA, Hemagglutinin; IP, immunoprecipitation. 
2007). However, ChIP-seq is limited by the quality of the antibody used as well as the abundance of the protein target itself, limiting ChIP-seq to the study of abundant targets.

Chromatin landscapes and, by extension, gene-expression profiles can also be surveyed through enzymatic methods that access open chromatin-DNA complexes, including DNase-, MNase-, and assay for transposable accessible chromatin (ATAC)-seq (Meyer and Liu 2014). These methods enable sequencing of transcriptionally active sites through ligation of NGS adaptors to isolated genomic DNA, which enables a broad picture of epigenetic and transcriptional heterogeneity. Given the highly dynamic nature of astrocytes and the complex transcriptional regulation involved in controlling pathogenic astrocyte pathways in disease, it will be interesting to identify how the epigenetic and transcriptional status of astrocytes changes over time. For example, one could envision that in MS, repressive histone marks are linked to AHR target genes in astrocytes, restricting the accessibility of AHR to anti-inflammatory genes. These approaches will prove valuable in future studies. In particular, ATACseq requires few cells $(500-50,000)$ as input (Buenrostro et al. 2013), which is compelling because it could enable profiling the transcriptional landscape of very small populations of molecularly heterogeneous astrocytes.

Probing gene-expression changes in astrocytes is essential for understanding their reprogramming in disease. A variety of exciting tools are available now that can begin to address this need. As discussed above, the RiboTag profiling method is an exciting approach to isolate mRNAs from well-defined target populations (Sanz et al. 2009). Indeed, this approach could also be useful in understanding the mechanisms that contribute to the pathogenesis of MS across different brain regions from the perspective of astrocytes or other cell types.

Identifying markers specific for specialized astrocyte populations are important to ultimately understand their function. Thus, the importance of regional heterogeneity must also be considered when evaluating the molecular and functional differences between astrocytes
(Molofsky et al. 2014; Ben Haim and Rowitch 2017). To this end, a recent study elegantly addressed this problem by evaluating regional and molecular astrocyte heterogeneity based on surface marker expression detected by flow cytometry (Lin et al. 2017). New single-cell sequencing techniques to assess transcriptional profiles (Jaitin et al. 2014; Klein et al. 2015; Macosko et al. 2015; Tao et al. 2015) or epigenetic status (Rotem et al. 2015) will likely provide useful insights regarding the heterogeneity of astrocytes in both health and disease.

\section{CONCLUDING REMARKS}

It is becoming increasingly clear that astrocytes play central roles in health and disease. Thus, it is important to define the molecular pathways that control astrocyte function. Indeed, recent findings by our group and others have started to define positive and negative regulators of astrocyte-driven pathogenesis in neurologic disorders. Positive regulators of astrocyte-driven pathogenesis drive the expression of transcriptional programs that contribute to disease pathogenesis, for example via the production of neurotoxic molecules such as nitric oxide (NO) and TNF- $\alpha$, or by recruiting neurotoxic inflammatory monocytes. Sphingolipid metabolism in astrocytes is an example of a positive regulator of astrocyte-driven pathogenesis (Mayo et al. 2014; Rothhammer et al. 2017b). Conversely, negative regulators of astrocyte-driven pathogenesis limit the expression of pathogenic transcriptional programs in astrocytes and may even drive the expression of neurotrophic and anti-inflammatory molecules. They are the functional equivalent to checkpoint inhibitors involved in limiting T-cell responses (Sharma and Allison 2015). AHR signaling in astrocytes is an example of a negative regulator of astrocyte-driven pathogenesis (Rothhammer et al. 2016).

The identification of disease-relevant positive or negative regulators of astrocyte-driven pathogenesis will guide the development of new therapeutic approaches based on their inhibition or stimulation, respectively. Based on the heterogeneity of astrocytes, it is important to determine whether these pathways define 
specific astrocyte subpopulations with opposing physiological roles. Moreover, it is important to determine the degree to which astrocyte populations are plastic in their phenotype and function. The plasticity of neurons (Flavell and Greenberg 2008), microglia (Shemer et al. 2015), and T cells (O'Shea and Paul 2010) is well known; thus, astrocyte plasticity is likely to contribute to the dynamic changes that occur in the inflamed CNS during the course of MS. New methods for genomic analysis at the single-cell level now provide a unique opportunity to investigate the heterogeneity, regulation, and therapeutic value of astrocytes in MS and other neurologic diseases.

\section{ACKNOWLEDGMENTS}

The authors thank all members of the Quintana Laboratory for helpful discussions. We offer our sincerest apologies to colleagues whose work we could not cite. M.A.W. is supported by T32CA207021 from the National Institutes of Health (NIH), F32NS101790 from the NIH, and a Traveling Neuroscience Fellowship from the Program in Neuroscience at Brigham \& Women's Hospital. F.J.Q. acknowledges funding provided by the NIH (NS087867, ES025530, AI126880, and AI093903), the National Multiple Sclerosis Society (RG4111A1 and JF2161-A-5), King Abdulaziz City for Science and Technology - Center for Excellence in Biomedicine Program, and from the International Progressive MS Alliance (PA-1604-08459).

\section{REFERENCES}

Allen NJ, Barres BA. 2009. Neuroscience: Glia-More than just brain glue. Nature 457: 675-677.

Allen NJ, Bennett ML, Foo LC, Wang GX, Chakraborty C, Smith SJ, Barres BA. 2012. Astrocyte glypicans 4 and 6 promote formation of excitatory synapses via GluA1 AMPA receptors. Nature 486: 410-414.

Anderson MA, Ao Y, Sofroniew MV. 2014. Heterogeneity of reactive astrocytes. Neurosci Lett 565: 23-29.

Anderson MA, Burda JE, Ren Y, Ao Y, O'Shea TM, Kawaguchi R, Coppola G, Khakh BS, Deming TJ, Sofroniew MV. 2016. Astrocyte scar formation aids central nervous system axon regeneration. Nature 532: 195-200.

Apetoh L, Quintana FJ, Pot C, Joller N, Xiao S, Kumar D, Burns EJ, Sherr DH, Weiner HL, Kuchroo VK. 2010.
The aryl hydrocarbon receptor interacts with c-Maf to promote the differentiation of type 1 regulatory $\mathrm{T}$ cells induced by IL-27. Nat Immunol 11: 854-861.

Barski A, Cuddapah S, Cui K, Roh TY, Schones DE, Wang Z, Wei G, Chepelev I, Zhao K. 2007. High-resolution profiling of histone methylations in the human genome. Cell 129: $823-837$.

Basso AS, Frenkel D, Quintana FJ, Costa-Pinto FA, PetrovicStojkovic S, Puckett L, Monsonego A, Bar-Shir A, Engel Y, Gozin M, et al. 2008. Reversal of axonal loss and disability in a mouse model of progressive multiple sclerosis. J Clin Invest 118: 1532-1543.

Bayraktar OA, Fuentealba LC, Alvarez-Buylla A, Rowitch DH. 2014. Astrocyte development and heterogeneity. Cold Spring Harb Perspect Biol 7: a020362.

Ben Haim L, Rowitch DH. 2017. Functional diversity of astrocytes in neural circuit regulation. Nat Rev Neurosci 18: $31-41$.

Bessede A, Gargaro M, Pallotta MT, Matino D, Servillo G, Brunacci C, Bicciato S, Mazza EM, Macchiarulo A, Vacca C, et al. 2014. Aryl hydrocarbon receptor control of a disease tolerance defence pathway. Nature 511: 184-190.

Blanco-Suarez E, Caldwell AL, Allen NJ. 2017. Role of astrocyte-synapse interactions in CNS disorders. J Physiol 595: 1903-1916.

Brancaccio M, Patton AP, Chesham JE, Maywood ES, Hastings MH. 2017. Astrocytes control circadian timekeeping in the suprachiasmatic nucleus via glutamatergic signaling. Neuron 93: 1420-1435.e1425.

Bruck W, Vollmer T. 2013. Multiple sclerosis: Oral laquinimod for MS - Bringing the brain into focus. Nat Rev Neurol 9: 664-665.

Buenrostro JD, Giresi PG, Zaba LC, Chang HY, Greenleaf WJ. 2013. Transposition of native chromatin for fast and sensitive epigenomic profiling of open chromatin, DNAbinding proteins and nucleosome position. Nat Methods 10: 1213-1218.

Buffington SA, Di Prisco GV, Auchtung TA, Ajami NJ, Petrosino JF, Costa-Mattioli M. 2016. Microbial reconstitution reverses maternal diet-induced social and synaptic deficits in offspring. Cell 165: 1762-1775.

Byron SA, Van Keuren-Jensen KR, Engelthaler DM, Carpten JD, Craig DW. 2016. Translating RNA sequencing into clinical diagnostics: Opportunities and challenges. Nat Rev Genet 17: 257-271.

Chang CY, Puga A. 1998. Constitutive activation of the aromatic hydrocarbon receptor. Mol Cell Biol 18: 525-535.

Charcot JM. 1868. Histologie de la sclérose en plaque [Histology of multiple sclerosis]. Gaz des Hôpitaux 41: 554555.

Chatterjee S, Alsaeedi N. 2012. Lactosylceramide synthase as a therapeutic target to mitigate multiple human diseases in animal models. Adv Exp Med Biol 749: 153-169.

Christopherson KS, Ullian EM, Stokes CC, Mullowney CE, Hell JW, Agah A, Lawler J, Mosher DF, Bornstein P, Barres BA. 2005. Thrombospondins are astrocyte-secreted proteins that promote CNS synaptogenesis. Cell 120: 421-433.

Chung WS, Clarke LE, Wang GX, Stafford BK, Sher A, Chakraborty C, Joung J, Foo LC, Thompson A, Chen C, et al. 2013. Astrocytes mediate synapse elimination 
M.A. Wheeler and F.J. Quintana

through MEGF10 and MERTK pathways. Nature 504: 394-400.

Dallerac G, Rouach N. 2016. Astrocytes as new targets to improve cognitive functions. Prog Neurobiol 144: 48-67.

De Keyser J, Laureys G, Demol F, Wilczak N, Mostert J, Clinckers R. 2010. Astrocytes as potential targets to suppress inflammatory demyelinating lesions in multiple sclerosis. Neurochem Int 57: 446-450.

Farez MF, Quintana FJ, Gandhi R, Izquierdo G, Lucas M, Weiner HL. 2009. Toll-like receptor 2 and poly(ADPribose) polymerase 1 promote central nervous system neuroinflammation in progressive EAE. Nat Immunol 10: 958-964.

Farez MF, Fiol MP, Gaitan MI, Quintana FJ, Correale J. 2015a. Sodium intake is associated with increased disease activity in multiple sclerosis. J Neurol Neurosurg Psychiatry 86: $26-31$.

Farez MF, Mascanfroni ID, Mendez-Huergo SP, Yeste A, Murugaiyan G, Garo LP, Balbuena Aguirre ME, Patel B, Ysrraelit MC, Zhu C, et al. 2015b. Melatonin contributes to the seasonality of multiple sclerosis relapses. Cell 162: 1338-1352.

Farez MF, Calandri IL, Correale J, Quintana FJ. 2016. Antiinflammatory effects of melatonin in multiple sclerosis. BioEssays 38: 1016-1026.

Flavell SW, Greenberg ME. 2008. Signaling mechanisms linking neuronal activity to gene expression and plasticity of the nervous system. Annu Rev Neurosci 31: 563-590.

Gabriely G, Wheeler MA, Takenaka MC, Quintana FJ. 2017. Role of AHR and HIF-1alpha in glioblastoma metabolism. Trends Endocrinol Metab 28: 428-436.

Gacias M, Gaspari S, Santos PM, Tamburini S, Andrade M, Zhang F, Shen N, Tolstikov V, Kiebish MA, Dupree JL, et al. 2016. Microbiota-driven transcriptional changes in prefrontal cortex override genetic differences in social behavior. eLife 5: 13442.

Gandhi R, Kumar D, Burns EJ, Nadeau M, Dake B, Laroni A, Kozoriz D, Weiner HL, Quintana FJ. 2010. Activation of the aryl hydrocarbon receptor induces human type 1 regulatory T cell-like and Foxp $3^{+}$regulatory T cells. Nat Immunol 11: 846-853.

Goverman J. 2009. Autoimmune T cell responses in the central nervous system. Nat Rev Immunol 9: 393-407.

Hsiao EY, McBride SW, Hsien S, Sharon G, Hyde ER, McCue T, Codelli JA, Chow J, Reisman SE, Petrosino JF, et al. 2013. Microbiota modulate behavioral and physiological abnormalities associated with neurodevelopmental disorders. Cell 155: 1451-1463.

Husemann J, Loike JD, Anankov R, Febbraio M, Silverstein SC. 2002. Scavenger receptors in neurobiology and neuropathology: Their role on microglia and other cells of the nervous system. Glia 40: 195-205.

Jaitin DA, Kenigsberg E, Keren-Shaul H, Elefant N, Paul F, Zaretsky I, Mildner A, Cohen N, Jung S, Tanay A, et al. 2014. Massively parallel single-cell RNA-seq for markerfree decomposition of tissues into cell types. Science 343: 776-779.

Jangi S, Gandhi R, Cox LM, Li N, von Glehn F, Yan R, Patel B, Mazzola MA, Liu S, Glanz BL, et al. 2016. Alterations of the human gut microbiome in multiple sclerosis. Nat Commun 7: 12015.
Johnson DS, Mortazavi A, Myers RM, Wold B. 2007. Genome-wide mapping of in vivo protein-DNA interactions. Science 316: 1497-1502.

Kaye J, Piryatinsky V, Birnberg T, Hingaly T, Raymond E, Kashi R, Amit-Romach E, Caballero IS, Towfic F, Ator MA, et al. 2016. Laquinimod arrests experimental autoimmune encephalomyelitis by activating the aryl hydrocarbon receptor. Proc Natl Acad Sci 113: E6145-E6152.

Khakh BS, Sofroniew MV. 2015. Diversity of astrocyte functions and phenotypes in neural circuits. Nat Neurosci 18: 942-952.

Klein AM, Mazutis L, Akartuna I, Tallapragada N, Veres A, Li V, Peshkin L, Weitz DA, Kirschner MW. 2015. Droplet barcoding for single-cell transcriptomics applied to embryonic stem cells. Cell 161: 1187-1201.

Lamas B, Richard ML, Leducq V, Pham HP, Michel ML, Da Costa G, Bridonneau C, Jegou S, Hoffmann TW, Natividad JM, et al. 2016. CARD9 impacts colitis by altering gut microbiota metabolism of tryptophan into aryl hydrocarbon receptor ligands. Nat Med 22: 598-605.

Lassmann H. 2014. Mechanisms of white matter damage in multiple sclerosis. Glia 62: 1816-1830.

Liddelow SA, Guttenplan KA, Clarke LE, Bennett FC, Bohlen CJ, Schirmer L, Bennett ML, Munch AE, Chung WS, Peterson TC, et al. 2017. Neurotoxic reactive astrocytes are induced by activated microglia. Nature 541: 481-487.

Lin CCJ, Yu K, Hatcher A, Huang TW, Lee HK, Carlson J, Weston MC, Chen F, Zhang Y, Zhu W, et al. 2017. Identification of diverse astrocyte populations and their malignant analogs. Nat Neurosci 20: 396-405.

Ludwin SK, Rao V, Moore CS, Antel JP. 2016. Astrocytes in multiple sclerosis. Mult Scler 22: 1114-1124.

Luhder F, Kebir H, Odoardi F, Litke T, Sonneck M, Alvarez JI, Winchenbach J, Eckert N, Hayardeny L, Sorani E, et al. 2017. Laquinimod enhances central nervous system barrier functions. Neurobiol Dis 102: 60-69.

Ma Z, Stork T, Bergles DE, Freeman MR. 2016. Neuromodulators signal through astrocytes to alter neural circuit activity and behaviour. Nature 539: 428-432.

Macosko EZ, Basu A, Satija R, Nemesh J, Shekhar K, Goldman M, Tirosh I, Bialas AR, Kamitaki N, Martersteck EM et al. 2015. Highly parallel genome-wide expression profiling of individual cells using nanoliter droplets. Cell 161: 1202-1214.

Mascanfroni ID, Takenaka MC, Yeste A, Patel B, Wu Y, Kenison JE, Siddiqui S, Basso AS, Otterbein LE, Pardoll DM, et al. 2015. Metabolic control of type 1 regulatory T cell differentiation by AHR and HIF1- $\alpha$. Nat Med 21: 638-646.

Matikainen T, Perez GI, Jurisicova A, Pru JK, Schlezinger JJ, Ryu HY, Laine J, Sakai T, Korsmeyer SJ, Casper RF, et al. 2001. Aromatic hydrocarbon receptor-driven Bax gene expression is required for premature ovarian failure caused by biohazardous environmental chemicals. Nat Genet 28: 355-360.

Mayo L, Trauger SA, Blain M, Nadeau M, Patel B, Alvarez JI, Mascanfroni ID, Yeste A, Kivisakk P, Kallas K, et al. 2014. Regulation of astrocyte activation by glycolipids drives chronic CNS inflammation. Nat Med 20: 1147-1156.

Mayo L, Cunha AP, Madi A, Beynon V, Yang Z, Alvarez JI, Prat A, Sobel RA, Kobzik L, Lassmann H, et al. 2016. 
IL-10-dependent $\operatorname{Tr} 1$ cells attenuate astrocyte activation and ameliorate chronic central nervous system inflammation. Brain 139: 1939-1957.

Metzker ML. 2010. Sequencing technologies-The next generation. Nat Rev Genet 11: 31-46.

Meyer CA, Liu XS. 2014. Identifying and mitigating bias in next-generation sequencing methods for chromatin biology. Nat Rev Genet 15: 709-721.

Mimran A, Mor F, Carmi P, Quintana FJ, Rotter V, Cohen IR. 2004. DNA vaccination with CD25 protects rats from adjuvant arthritis and induces an antiergotypic response. J Clin Invest 113: 924-932.

Molofsky AV, Kelley KW, Tsai HH, Redmond SA, Chang SM, Madireddy L, Chan JR, Baranzini SE, Ullian EM, Rowitch DH. 2014. Astrocyte-encoded positional cues maintain sensorimotor circuit integrity. Nature 509: 189-194.

Nair A, Frederick TJ, Miller SD. 2008. Astrocytes in multiple sclerosis: A product of their environment. Cell Mol Life Sci 65: 2702-2720.

O'Shea JJ, Paul WE. 2010. Mechanisms underlying lineage commitment and plasticity of helper $\mathrm{CD} 4^{+} \mathrm{T}$ cells. Science 327: 1098-1102.

Palma JA, Pagola I. 2012. Oral laquinimod for multiple sclerosis. N Engl J Med 366: 2527; author reply 2527-2528.

Platten M, Ho PP, YoussefS, Fontoura P, Garren H, Hur EM, Gupta R, Lee LY, Kidd BA, Robinson WH, et al. 2005. Treatment of autoimmune neuroinflammation with a synthetic tryptophan metabolite. Science 310: 850-855.

Quintana FJ. 2013a. The aryl hydrocarbon receptor: A molecular pathway for the environmental control of the immune response. Immunology 138: 183-189.

Quintana FJ. 2013b. Regulation of central nervous system autoimmunity by the aryl hydrocarbon receptor. Semin Immunopathol 35: 627-635.

Quintana FJ. 2014. LeA(H)Rning self-control. Cell Res 24 1155-1156.

Quintana FJ, Sherr DH. 2013. Aryl hydrocarbon receptor control of adaptive immunity. Pharmacolog Rev 65: 1148-1161.

Rotem A, Ram O, Shoresh N, Sperling RA, Goren A, Weitz DA, Bernstein BE. 2015. Single-cell ChIP-seq reveals cell subpopulations defined by chromatin state. Nat Biotechnol 33: 1165-1172.

Rothhammer V, Quintana FJ. 2015. Control of autoimmune CNS inflammation by astrocytes. Semin Immunopathol 37: 625-638.

Rothhammer V, Quintana FJ. 2016. Environmental control of autoimmune inflammation in the central nervous system. Curr Opin Immunol 43: 46-53.

Rothhammer V, Mascanfroni ID, Bunse L, Takenaka MC, Kenison JE, Mayo L, Chao CC, Patel B, Yan R, Blain M, et al. 2016. Type I interferons and microbial metabolites of tryptophan modulate astrocyte activity and central nervous system inflammation via the aryl hydrocarbon receptor. Nat Med 22: 586-597.

Rothhammer V, Borucki DM, Garcia Sanchez MI, Mazzola MA, Hemond CC, Regev K, Paul A, Kivisäkk P, Bakshi R, Izquierdo G, et al. 2017a. Dynamic regulation of serum aryl hydrocarbon receptor agonists in multiple sclerosis. Neurol Neuroimmunol Neuroinflamm 4: e359.
Rothhammer V, Kenison JE, Tjon E, Takenaka MC, de Lima KA, Borucki DM, Chao CC, Wilz A, Blain M, Healy L, et al. 2017b. Sphingosine 1-phosphate receptor modulation suppresses pathogenic astrocyte activation and chronic progressive CNS inflammation. Proc Natl Acad Sci 114: 2012-2017.

Sanz E, Yang L, Su T, Morris DR, McKnight GS, Amieux PS. 2009. Cell-type-specific isolation of ribosome-associated mRNA from complex tissues. Proc Natl Acad Sci 106: 13939-13944.

Seifert G, Schilling K, Steinhauser C. 2006. Astrocyte dysfunction in neurological disorders: A molecular perspective. Nat Rev Neurosci 7: 194-206.

Sharma P, Allison JP. 2015. The future of immune checkpoint therapy. Science 348: 56-61.

Shemer A, Erny D, Jung S, Prinz M. 2015. Microglia plasticity during health and disease: An immunological perspective. Trends Immunol 36: 614-624.

Shendure J, Ji H. 2008. Next-generation DNA sequencing. Nat Biotechnol 26: 1135-1145.

Silver J, Miller JH. 2004. Regeneration beyond the glial scar. Nat Rev Neurosci 5: 146-156.

Sofroniew MV. 2015. Astrocyte barriers to neurotoxic inflammation. Nat Rev Neurosci 16: 249-263.

Sofroniew MV, Vinters HV. 2010. Astrocytes: Biology and pathology. Acta Neuropathol 119: 7-35.

Srinivasan R, Huang BS, Venugopal S, Johnston AD, Chai H, Zeng H, Golshani P, Khakh BS. 2015. $\mathrm{Ca}^{2+}$ signaling in astrocytes from Ip $3 \mathrm{r}^{-/-}$mice in brain slices and during startle responses in vivo. Nat Neurosci 18: 708-717.

Steinman L. 2009. A molecular trio in relapse and remission in multiple sclerosis. Nat Rev Immunol 9: 440-447.

Steinman L. 2014. Immunology of relapse and remission in multiple sclerosis. Annu Rev Immunol 32: 257-281.

Stevens B, Allen NJ, Vazquez LE, Howell GR, Christopherson KS, Nouri N, Micheva KD, Mehalow AK, Huberman AD, Stafford B, et al. 2007. The classical complement cascade mediates CNS synapse elimination. Cell 131: 1164-1178.

Stockinger B, Di Meglio P, Gialitakis M, Duarte JH. 2014. The aryl hydrocarbon receptor: Multitasking in the immune system. Annu Rev Immunol 32: 403-432.

Stys PK, Zamponi GW, van Minnen J, Geurts JJ. 2012. Will the real multiple sclerosis please stand up? Nat Rev Neurosci 13: 507-514.

Takenaka MC, Robson S, Quintana FJ. 2016. Regulation of the T cell response by CD39. Trends Immunol 37: 427439.

Tao Y, Rotem A, Zhang H, Chang CB, Basu A, Kolawole AO, Koehler SA, Ren Y, Lin JS, Pipas JM, et al. 2015. Rapid, targeted and culture-free viral infectivity assay in dropbased microfluidics. Lab Chip 15: 3934-3940.

Toft-Hansen H, Fuchtbauer L, Owens T. 2011. Inhibition of reactive astrocytosis in established experimental autoimmune encephalomyelitis favors infiltration by myeloid cells over T cells and enhances severity of disease. Glia 59: $166-176$

Varrin-Doyer M, Zamvil SS, Schulze-Topphoff U. 2014. Laquinimod, an up-and-coming immunomodulatory agent for treatment of multiple sclerosis. Exp Neurol 262: 66-71. 
M.A. Wheeler and F.J. Quintana

Vollmer TL, Sorensen PS, Selmaj K, Zipp F, Havrdova E, Cohen JA, Sasson N, Gilgun-Sherki Y, Arnold DL, Group BS. 2014. A randomized placebo-controlled phase III trial of oral laquinimod for multiple sclerosis. J Neurol 261: 773-783.

Voskuhl RR, Peterson RS, Song B, Ao Y, Morales LB, TiwariWoodruff S, Sofroniew MV. 2009. Reactive astrocytes form scar-like perivascular barriers to leukocytes during adaptive immune inflammation of the CNS. J Neurosci 29: 11511-11522.

Wu HY, Quintana FJ, da Cunha AP, Dake BT, Koeglsperger T, Starossom SC, Weiner HL. 2011. In vivo induction of Tr1 cells via mucosal dendritic cells and AHR signaling. PLOS ONE 6: e23618.
Xie L, Yang SH. 2015. Interaction of astrocytes and T cells in physiological and pathological conditions. Brain Res 1623: 63-73.

Yeste A, Takenaka MC, Mascanfroni ID, Nadeau M, Kenison JE, Patel B, Tukpah AM, Babon JA, DeNicola M, Kent SC et al. 2016. Tolerogenic nanoparticles inhibit T cell-mediated autoimmunity through SOCS2. Sci Signal 9: ra61.

Zamanian JL, Xu L, Foo LC, Nouri N, Zhou L, Giffard RG, Barres BA. 2012. Genomic analysis of reactive astrogliosis. J Neurosci 32: 6391-6410.

Zhang I, Alizadeh D, Liang J, Zhang L, Gao H, Song Y, Ren H, Ouyang M, Wu X, D’Apuzzo M, et al. 2016. Characterization of arginase expression in glioma-associated microglia and macrophages. PLoS ONE 11: e0165118. 


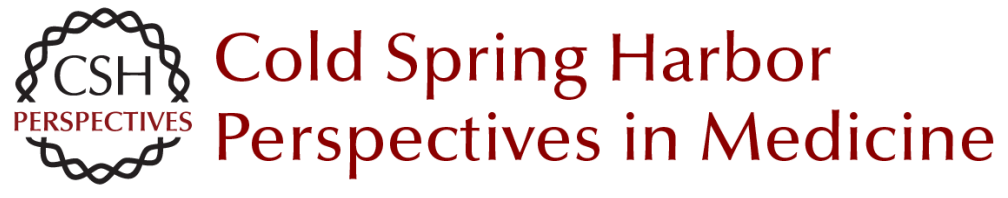

\section{Regulation of Astrocyte Functions in Multiple Sclerosis}

Michael A. Wheeler and Francisco J. Quintana

Cold Spring Harb Perspect Med 2019; doi: 10.1101/cshperspect.a029009 originally published online January 22, 2018

\section{Subject Collection Multiple Sclerosis}

\section{Multiple Sclerosis Pathology}

Hans Lassmann

Regulatory T Cells: From Discovery to

Autoimmunity

Alexandra Kitz, Emily Singer and David Hafler

The Multiple Roles of B Cells in Multiple Sclerosis

and Their Implications in Multiple Sclerosis

Therapies

Rui Li and Amit Bar-Or

Autologous Hematopoietic Stem Cell

Transplantation in the Treatment of Multiple

Sclerosis

Carolina A. Rush, Harold L. Atkins and Mark S.

Freedman

B-Cell Therapies in Multiple Sclerosis

Joseph J. Sabatino, Jr., Scott S. Zamvil and Stephen L. Hauser

Oral Therapies for Multiple Sclerosis Simon Faissner and Ralf Gold

Interferon $\beta$ for Multiple Sclerosis

Dejan Jakimovski, Channa Kolb, Murali

Ramanathan, et al.

Alemtuzumab as Treatment for Multiple Sclerosis Serafeim Katsavos and Alasdair Coles

\author{
Natalizumab: Perspectives from the Bench to \\ Bedside \\ Afsaneh Shirani and Olaf Stüve \\ Daclizumab Therapy for Multiple Sclerosis \\ Bibiana Bielekova
}

\section{Lifestyle and Environmental Factors in Multiple \\ Sclerosis \\ Lars Alfredsson and Tomas Olsson \\ Biomarkers in Multiple Sclerosis \\ Anu Paul, Manuel Comabella and Roopali Gandhi}

The Evolving Mechanisms of Action of Glatiramer
Acetate

Thomas Prod'homme and Scott S. Zamvil

Regulation of Astrocyte Functions in Multiple Sclerosis

Michael A. Wheeler and Francisco J. Quintana

Experimental Autoimmune Encephalomyelitis

(EAE) as Animal Models of Multiple Sclerosis (MS)

Simon Glatigny and Estelle Bettelli

Neurodegeneration in Progressive Multiple

Sclerosis

Graham Campbell and Don Mahad

For additional articles in this collection, see http://perspectivesinmedicine.cshlp.org/cgi/collection/ 